\title{
Use of Seawater and Pesticides (Geunsami and Pullmagi Gold) for Suppressing Growth of Spartina anglica and Their Effects on Soil Stability
}

\author{
Eun-Suk Lee1), Jae-Young Byun"1), Maynanda Brigita Chrysta ${ }^{1)}$, Okenkwu Nnaemeka Nicholas ${ }^{1)}$, \\ Se-Young Lee ${ }^{2)}$, Won-Sik Choi ${ }^{3)}$
}

\begin{abstract}
Common cordgrass (Spartina anglica) is a harmful marine organism that has proved to be a serious invasive species causing extensive damage to natural saltmarsh ecosystems in many areas. In order to reduce the damage that may occur from spreading these plants, it takes the best steps to destroy them. In this study, an experiment of Spartina anglica growth suppression was carried out. The media used to eradicate these weeds were seawater concentrate and pesticides (Pullmagi gold and Geunsami). In testing Spartina anglica and clover growth inhibition, samples were planted in mudflats A, B, and C. In mudflats (A) sprayed seawater concentrate using 5L stock solution, (B) sprayed 5L liquid herbicide and $25 \mathrm{ml}$ pesticides, and (C) sprayed liquid herbicide $5 \mathrm{~L}$ and $50 \mathrm{ml}$ pesticides. As a result, after 5 days of spraying, the growth inhibition of the sliding plant showed that variation (A) with seawater concentrate showed rapid growth inhibition, while for variation (B) and (C) that using herbicides did not show growth inhibition. The change in growth inhibition on variation A was remarkable. The seawater concentrate showed growth inhibition of whole leaves after 1 day. The results of the five heavy metals analysis of soils were also not detected and the growth inhibition and safety of plants after the experiments are analyzed in the sludge and seagrass of sea soils.
\end{abstract}

Keywords: Spartina Anglica, Seawater Concentrate, Pesticide, Growth Inhibition, Stability Soil

\section{Introduction}

Common cordgrass (Spartina anglica) is a harmful marine organism that has proved to be a serious invasive species causing extensive damage to natural saltmarsh ecosystems in many areas. Spartina anglica is also known as a perennial plant of Poaceae, originating from the

Received(September 18, 2019), Review Result(1st: October 13, 2019, 2nd: November 27, 2019), Accepted(January 30, 2020)

1) (Student) 50463 Dept. Bio Industrial Machinery Engineering, Pusan National University, Miryang, Korea email: suk099@hanmail.net

2) (President) 45211 Yeorumul Co. Ltd., Incheon, Korea

email: yeorumul@naver.com

3) (Professor, Corresponding Author) 50463 Dept. Bio Industrial Machinery Engineering, Pusan National University, Miryang, Korea

email: choi@pusan.ac.kr 
Growth Suppression The Weeds and Stability on The Sail Using Low-contained Natural Salt-liquid and Pesticides (Geunsami, Pullmagi Gold)

North Atlantic coast of Newfoundland, south of Canada, in the mudflats of northern Argentia, and distributed in wet and salty mudflats and brackish water. This plant is also distributed in inland wetlands, swamps, and dry grasslands. The inflow path of Spartina anglica (sponge) is found in Jinju, South Chungcheong Province, Ansan, Gyeonggi Province, Yeongjong Island in Incheon, and Ganghwa Island[1].

The very wide and continuous spread of these plants is known can destroy other plant habitats and reduce the amount of sunlight that reaches the mudflat surface. This result can lead to degradation of micro-algae production and habitat loss due to grassroots in low species. In addition, this plant is also known to disrupt marine ecosystems. For example, the growth of this plant in 2012 has expanded to $130 \mathrm{~m}^{2}$ degrees and occupies natural waters in China[2]. Therefore, handling to inhibit the spread of this plant needs to be done.

The rate of spread at individual sites has also varied greatly but in many areas has involved the rapid spread from transplants or other propagating units to form a continuous sward. Within several decades this alien species was frequently observed along the entire German Wadden Sea coast[3]. This plant has been intentionally introduced to coastal and estuarine mudflats throughout the world. The species has proven to be highly invasive in many parts of the world and there is much concern about its spread on the Pacific coast of North America, in East Asia, New Zealand and Australia (incl. Tasmania)[4]. Some of the significant ecologically harmful effects of S. anglica, in general, are a loss of rearing habitat for fish, alteration the course of succession, and replacement of native plants and more diverse native plant communities[4].

In the previous study, Zhu et al.[5] reported that the rapid invasion of Spartina sp. to the coastal wetlands of Chine has attracted much attention. Hyun et al. were also has reported that in Korea, especially in Ganghwa intertidal wetlands, the invasion of Spartina anglica also happened so fast that it replaced the native $S$. japanica population in the area[6]. In the study, it was also said that the presence of $S$. anglica not only caused ecological and environmental problems but was also predicted to have an impact on salt marsh plants on biogeochemical processes in Ganghwa intertidal sediments.

Considering the negative effect of arising from the spread of this plant, it is a good idea to choose the best way for eradication in order to reduce the negative effects caused. In this study, it was used high concentrated seawater which is made from eco-friendly materials, harmless to the human body, with $100 \%$ minerals, and there are no heavy metals and harmful E. coli bacteria. The use of this material was chosen by considering to find a solution to the existing problem, while still minimizing the possibility of other problems arising. As a liquid, 
the main ingredient is sodium chloride; minerals, such as magnesium, sulfur, zinc, and selenium; and osmotic microorganisms such as indigenous biodegradation strains, marine microalgae, etc. are highly useful and powerful osmotic phenomena. After spraying with a liquid to make the leaves decomposed about a week, the plant's growth was suppressed after one month.

\section{Materials and Methods}

\subsection{Materials}

Seawater concentrated (Incheon area Yrotumul), Spartina anglica (Ganghwa-do dongmag), clover (Miryang), Pullmagi gold, Geunsami (Miryang Imcheon pesticide), strength tester, salinity tester, $\mathrm{pH}$ meter (Fig .1). The selection of clover as an object in this study was done because this plant is considered as one of the types of vegetation that also dominates agricultural land in Korea which is sometimes considered a pest.

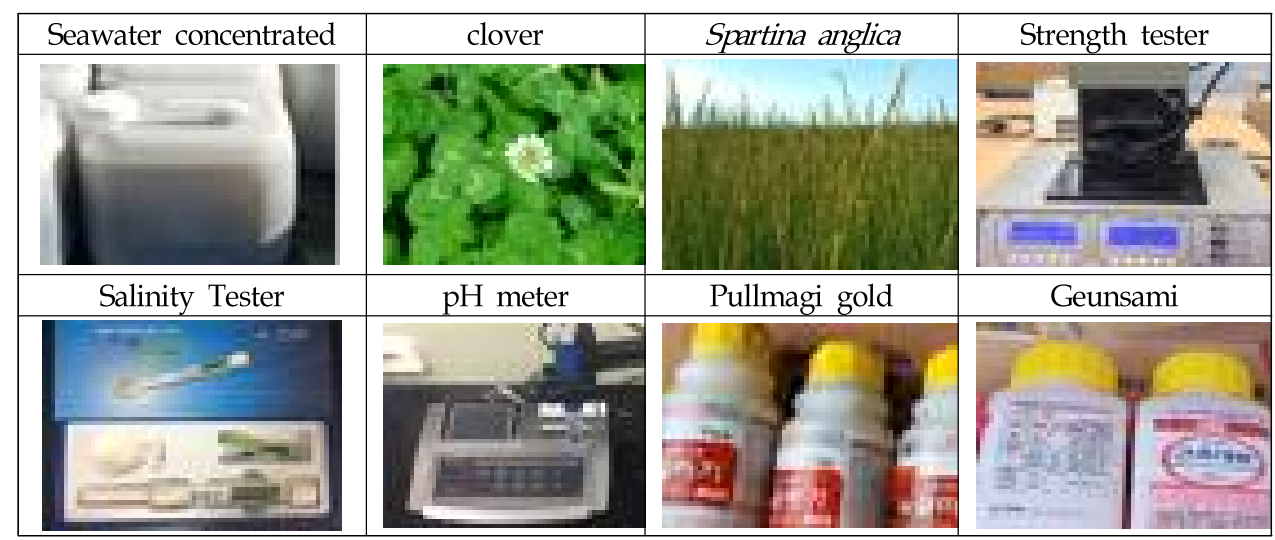

[Fig. 1] Materials Used for Experiment

\subsection{Methods}

The physical means of preventing Spartina anglica, can be extracted by hand or by using a shovel. While chemically it can be done using a non-selective herbicide, Glyphosate. Glyphosate is a non-selective foliage herbicide that inhibits 5-enolpyruvyl shikimate-3-phosphate synthase (EPSPS) of aromatic amino acid biosynthesis. Imazapyr has been applied to remove the imidazolinone compound that inhibits acetolactate synthase (ALS), the first enzyme in the 
Growth Suppression The Weeds and Stability on The Sail Using Low-contained Natural Salt-liquid and Pesticides (Geunsami, Pullmagi Gold)

biosynthesis of branched amino acids (Leucine, valine, isoleucine). Human resources, money, and time wasted are the key to treat mudflats with chemical treatment. In this study, removal of strange Spartina anglica and clover was carried out using herbicides (Pullmagi gold, Geunsami) and seawater. This was used to present necessary data to demonstrate that the concentration of glyphosate and the amount of salt in the soil are below the standard level.

Seawater was evaporated from the natural evaporation area of the Spartina anglica only by solar heat to obtain highly concentrated natural salts. Herbicides $(1500 \mathrm{~mL})$ was produced with a different ratio of water. The ratio of water for sample A1, A2, and A3 were shown in Table 1. In order to suppress the growth of plants, a space of $1 \mathrm{~m}$ by $1 \mathrm{~m}$ in each of the open spaces was secured from a lot of clover and light, then herbicides were sprayed at $1500 \mathrm{~m}$ each time and observed until the grass was suppressed every 24 hours.

[Table 1] Seawater Concentrate and Water Ratio

\begin{tabular}{|c|c|c|}
\hline & Seawater concentrate & water \\
\hline A1 & 1 & 0 \\
\hline A2 & 1 & 1 \\
\hline A3 & 1 & 2 \\
\hline
\end{tabular}

2. Visited Dongmak-ri, Ganghwado Island to create an experimental zone with $1800 \mathrm{~m} \times 1800 \mathrm{~m}$ in dense areas where Spartina anglica was growing. In this study, there were 3 step observation (Table 2), strength tests, growth inhibitory effects, $\mathrm{pH}$ of seawater soil, salinity measurements, and root-comparison tests.

[Table 2] Nacl, Rare Earth Metals, Seawater Concentrate Ratio

\begin{tabular}{|c|c|c|c|}
\hline & Step.1 & Step.2 & Step.3 \\
\hline $\begin{array}{c}\text { Sponge } \\
\text { Growth Inhibition Experiment }\end{array}$ & Nacl $125 \mathrm{~kg}$ & Rare earth metals $10 \mathrm{~kg}$ & $\begin{array}{c}\text { Seawater concentrate } \\
100 \mathrm{~kg}\end{array}$ \\
\hline
\end{tabular}

3. The volume of seawater concentrate and herbicide (Pullmagi gold, Geunsami) used on samples A, B, and C are shown in Table.3. In the experiment for plant growth inhibition, the herbicide was sprayed three times every 10 days for Spartina anglica and the seawater concentrate was sprayed once every 10 days for clover. As a result of the spraying, it was completely killed after 1 day and was not administered anymore. The herbicide was sprayed more than twice to fully inhibit growth and observed the contamination of the soil and the ingredients of the Glyphosate density, salt density, and colorimeter. 
[Table 3] Seawater Concentrate and Herbicide Volume Used

\begin{tabular}{|c|c|c|c|}
\hline & Seawater concentrate1 & Fulmagi gold & Geunsame \\
\hline A & $5 \mathrm{~L}$ & Water5L+25ML & Water5L+50ML \\
\hline B & $5 \mathrm{~L}$ & Water5L+25ML & Water5L+50ML \\
\hline C & $5 \mathrm{~L}$ & Water5L+25ML & Water5L+50ML \\
\hline
\end{tabular}

\section{Results and Discussion}

1. The ratio of seawater concentration to water for $\mathrm{A} 1, \mathrm{~A} 2, \mathrm{~A} 3$, respectively, and the picture of spraying results into the clover are shown in [Fig. 2] below. [Fig. 2] (a), (b), and (c) were clover conditions before spraying the seawater concentrates, whereas [Fig. 2] (d), (e), and (f) were the clover conditions after three days spraying A1, A2, and A3 solutions. In [Fig. 2] (d) that only used $100 \%$ of the seawater concentration solution, it can be seen that it was possible to make the clover being completely growth inhibited. In [Fig. 2] (e) was showed $90 \%$ inhibited growth as a solution with water and dilution ratio of 1:1. While in [Fig. 2] (f) where was used a solution with twice as much water as a ratio of $1: 2$ showed that only $50 \%$ of the growth inhibited.

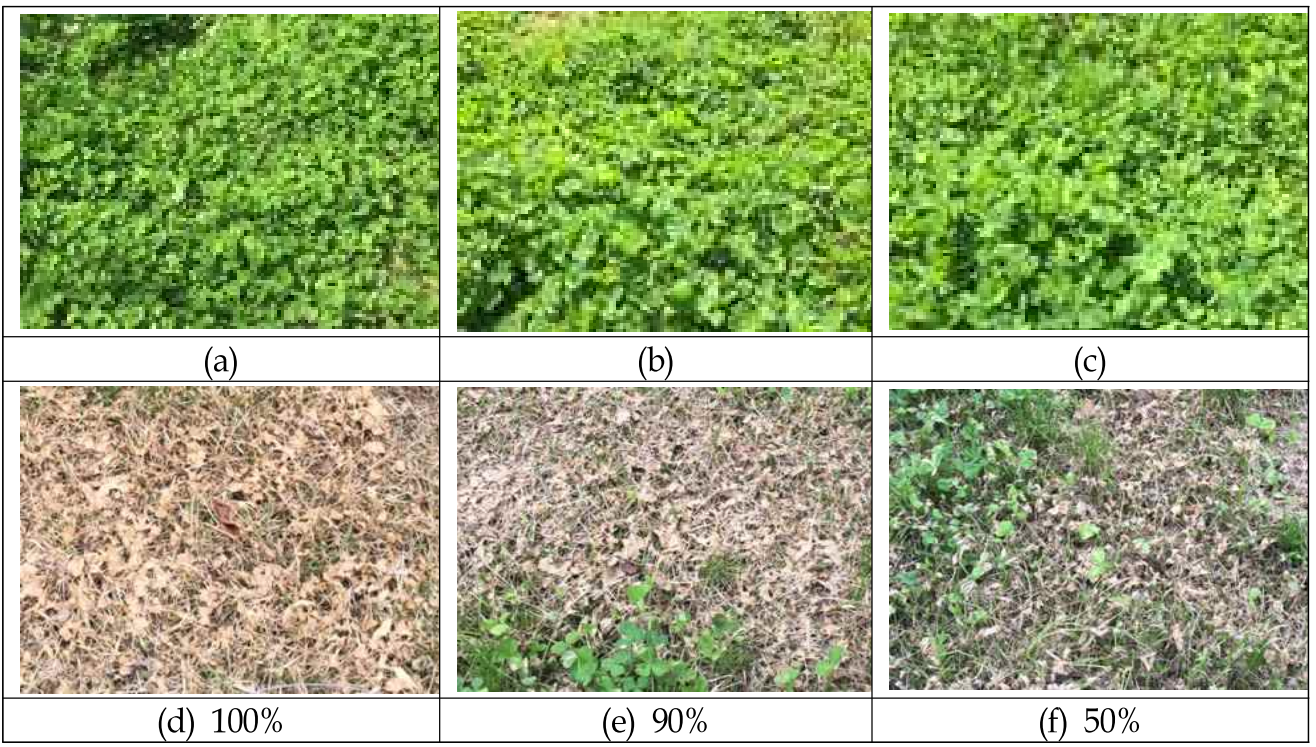

[Fig. 2] Result of Colver Sprayed with Seawater Comcentrate

2. To test the strength of the Spartina anglica, the plant was divided by flowers, leaves, and stem roots. The $100 \mathrm{~mm}$ leaves and three stems were prepared. In total, 12 experiments were 
Growth Suppression The Weeds and Stability on The Sail Using Low-contained Natural Salt-liquid and Pesticides (Geunsami, Pullmagi Gold)

conducted with $23 \mathrm{~kg}$ of Spartina anglica and $15 \mathrm{~kg}$ of the grasses. The area of $1800 \mathrm{~mm} \times$ $1800 \mathrm{~mm}$, as shown in [Fig. 3], (a) 3 step area was made, Nacl $125 \mathrm{~g}$ sprayed in (b) area, $10 \mathrm{~kg}$ of Rare earth metals in (c) area, $100 \mathrm{~kg}$ of seawater concentrate in (d) area, and $100 \mathrm{~kg}$ of seawater in (e) area. As a result of the inhibition of growth, the death was fast in the $100 \mathrm{~kg}$ of seawater concentrate, and the $\mathrm{pH}$ and salinity of the seawater and soil of (f) were collected. The $\mathrm{pH}$ obtained of sample results was $7.3 \pm 8.1$, which does not exceed the $\mathrm{pH}$ concentration threshold of $6.0 \sim 8.5$. The soil pollution level was also lower than that of cadmium and five heavy metals. Samples of seaweed are collected at the site and are found to be safe for soil and seawater because they are not detected in the five heavy metals (sodium chloride, cadmium, lead, mercury arsenic) in seawater. Heavy metals including lead, nickel, cadmium, copper, cobalt, chromium and mercury are important environmental pollutants that cause toxic effects to plants; thus, lessening productivity and posing dangerous threats to the agro-ecosystems. They act as stress to plants and affect plant physiology[5].

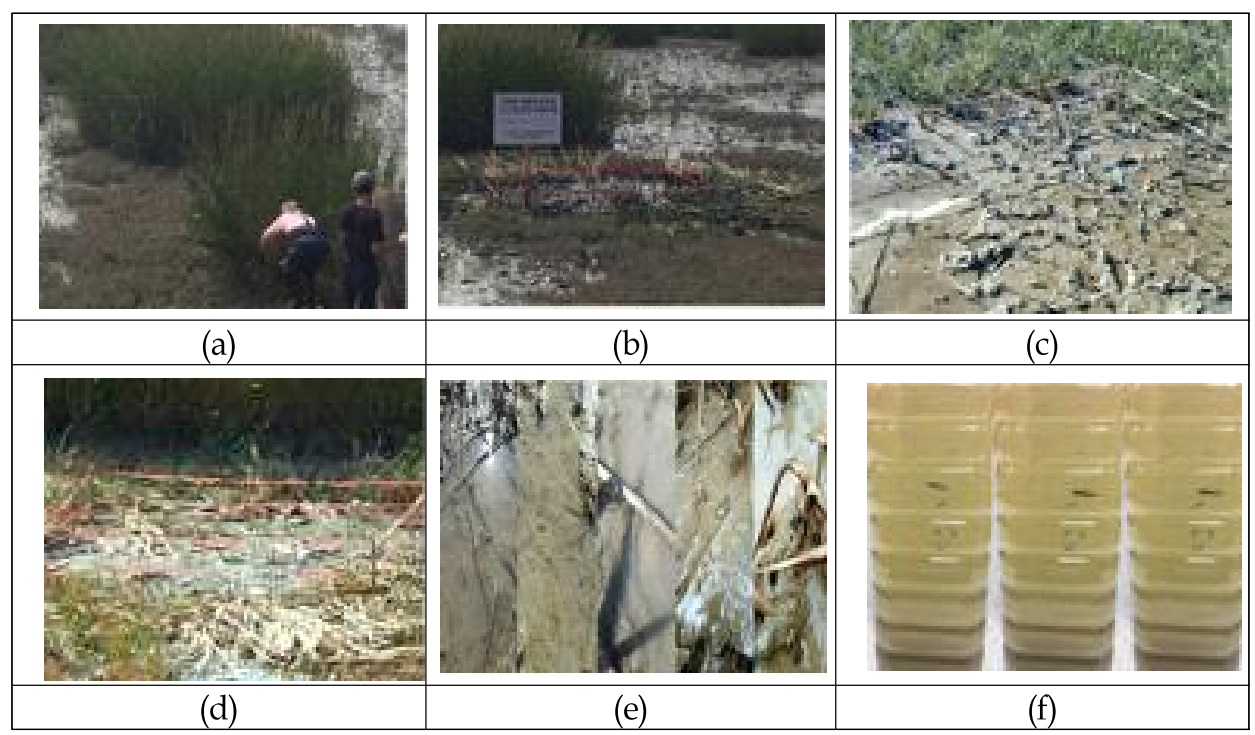

[Fig. 3] Plant Growth Inhibition Changes during Process

3. Figures of seawater concentrate and herbicide (Pullmagi gold, Geunsami) when sprayed with seawater concentrated (A), Pullmagi gold (B), and Geunsami (C) on Spartina anglica and clover are shown in [Fig. 4], respectively. The seawater concentrated was sprayed twice every 10 days, the herbicide was sprayed three times every 10 days, and the plant growth inhibited. For the clover, the seawater concentration was sprayed once to suppress plant growth, and the herbicide was sprayed three times every three days. 


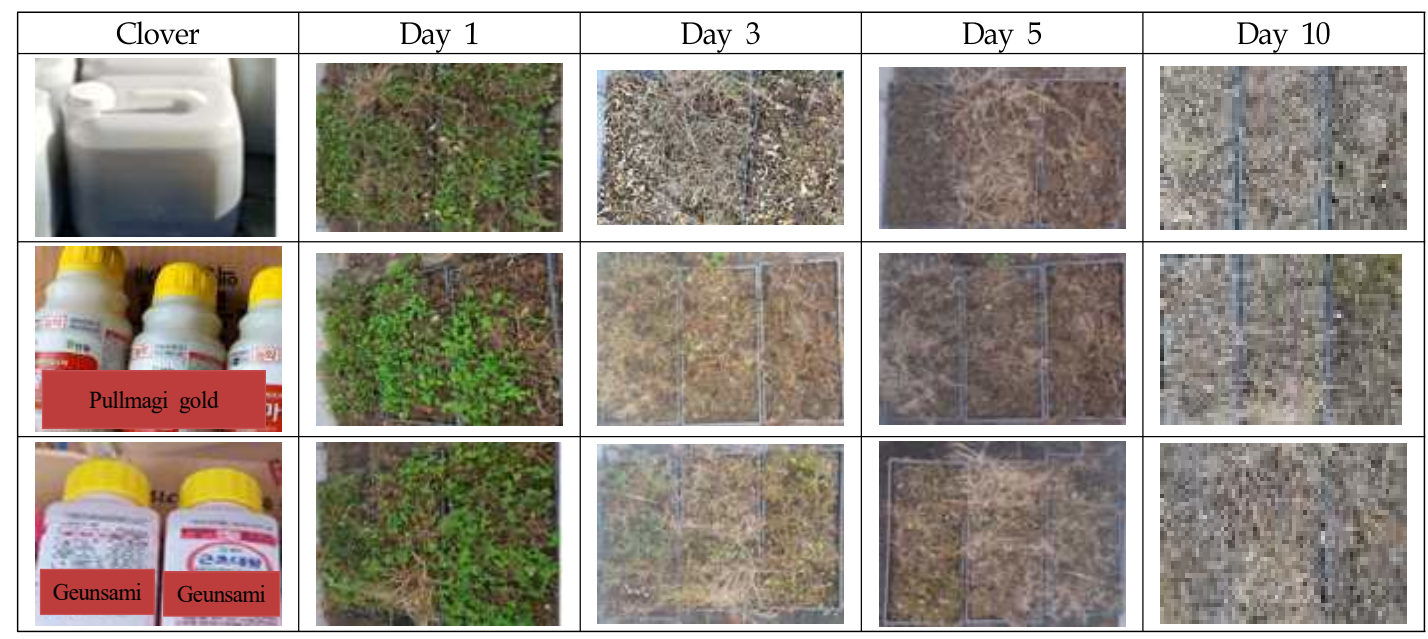

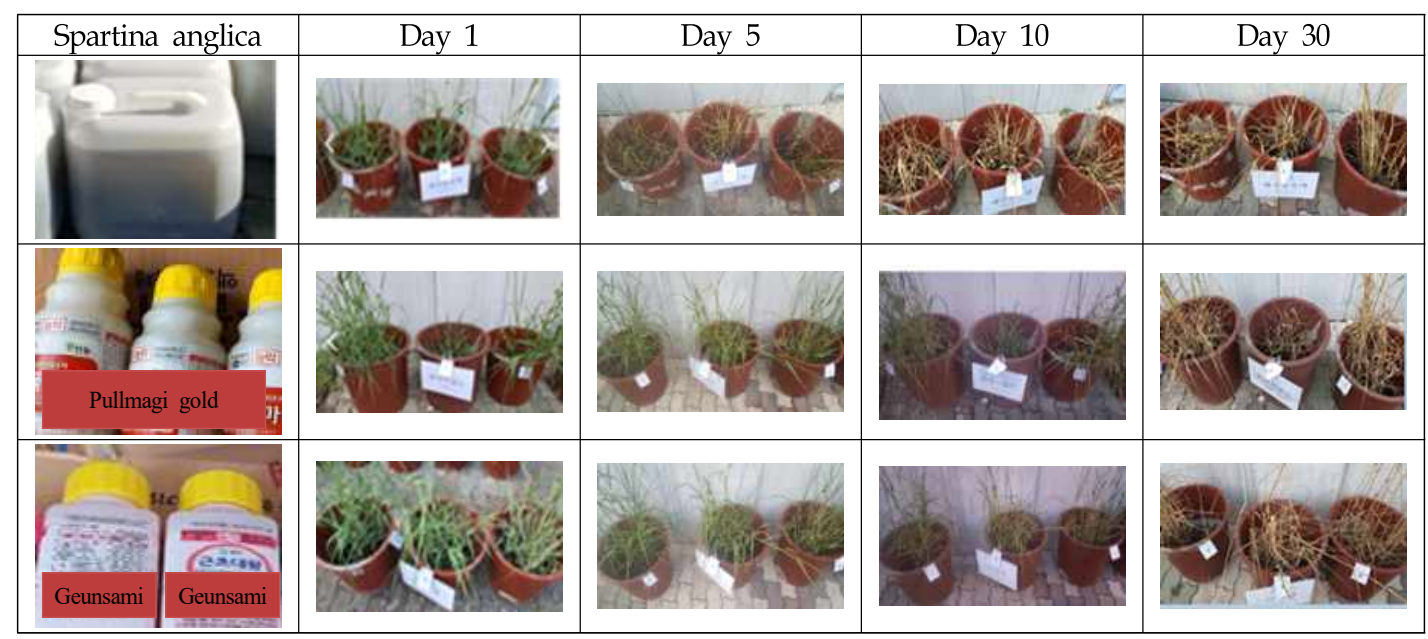

[Fig. 4] Plant Growth Inhibition Changes during Process

The analysis results for sea soil $500 \mathrm{~g}$ and general soil $500 \mathrm{~g}$ before the application of two seaweed concentrate herbicides are shown in [Fig. 5]. Five major metals test results showed that cadmium was not detected, while the other results were higher in general soil than in sea soil. However, it still was much lower than the permissible level.

The detection of cadmium after spraying was $0.17 \mathrm{mg} / \mathrm{kg}$ above the permissible level in Pullmagi gold and the content of copper was lower than the acceptable standard. As a result of the results to check the nutritional status of the soil. [Fig. 6] showed that the Spartina anglica 
Growth Suppression The Weeds and Stability on The Sail Using Low-contained Natural Salt-liquid and Pesticides (Geunsami, Pullmagi Gold)

sprayed with seawater concentrate also contains high magnesium conductivity and high magnesium content in clover.

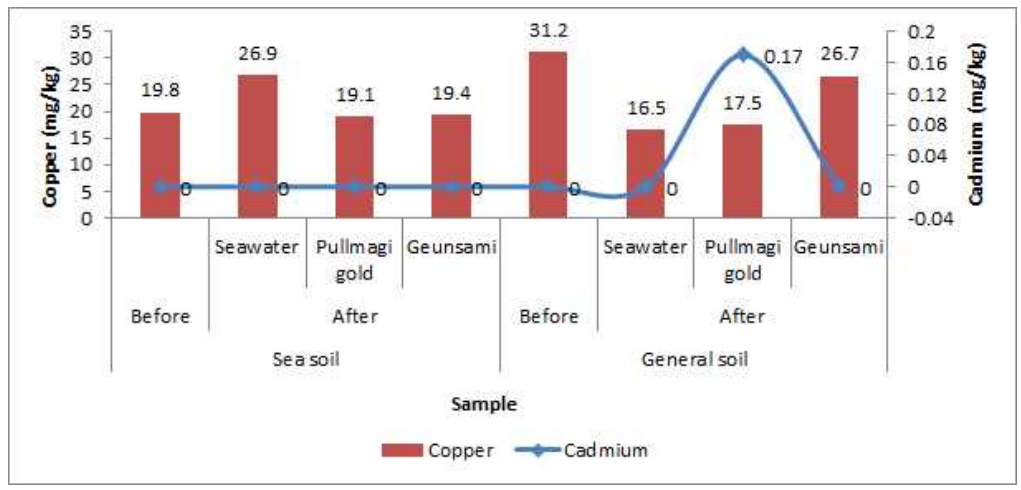

[Fig. 5] Soil Comparison Before Spraying Seawater Concentration

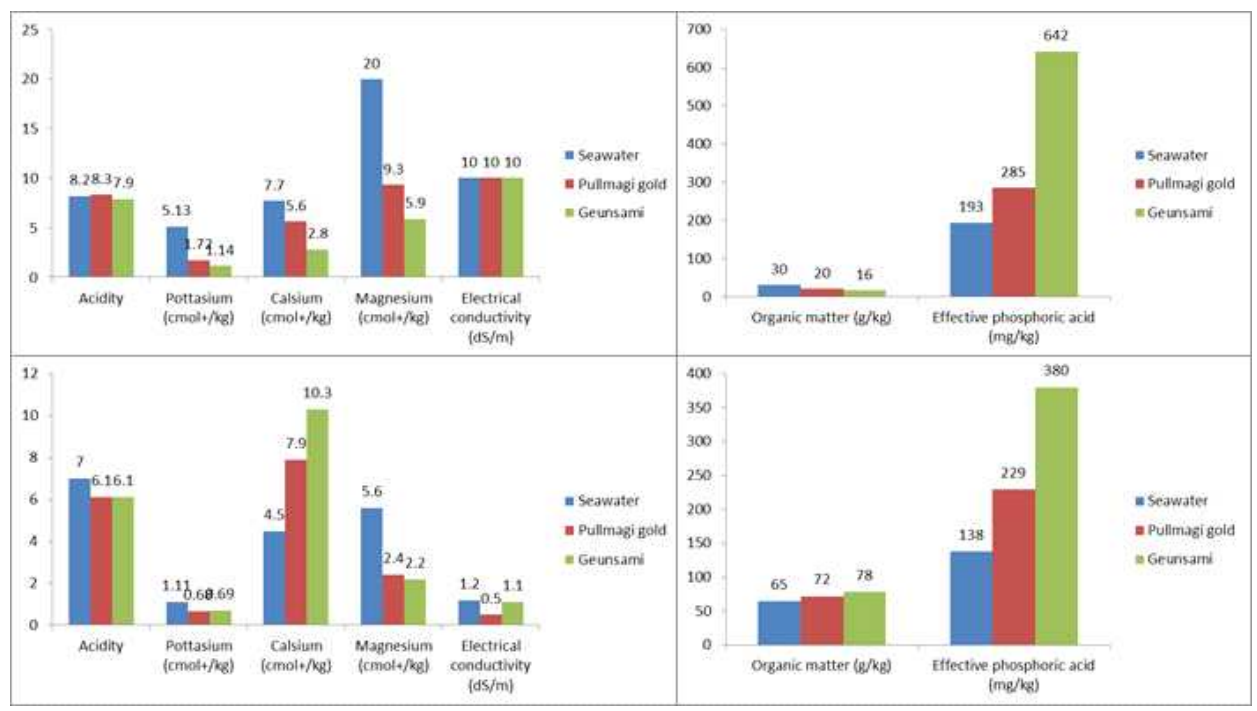

[Fig. 6] Soil Nutrition After Spraying

The phenomenon of plant growth inhibition in adipose synthesis, protein synthesis, disruption of amino acid production, chlorophyll disruption, and photosynthesis was analyzed by the colorimeter. The value of Spartina anglica before spraying seawater was 38.52, but growth inhibition of Spartina anglica after 2 months was reduced by seawater, Pullmagi gold, and Geunsami.

The glyphosate concentrations of the seawater concentrate and the results of the pesticides are shown in [Fig. 7]. As shown in [Fig. 7], the glyphosate density was lower than the standard in the Korea Institute of Construction and Living Environment Testing, and it was not 
detected in the results of 320 kinds of pesticides in the agricultural research institute.

[Table 4] Plant Growth Inhibition Reaction with Colorimeter

\begin{tabular}{|c|c|c|c|c|}
\hline Sample name & $\mathrm{L}^{*}$ & $\mathrm{a}^{*}$ & $\mathrm{~b}^{*}$ & Average \\
\hline sponge & 38.52 & -5.63 & 19.07 & \\
\hline Seawater concentrate1 & 55.24 & 7.43 & 29.02 & 23.43 \\
\hline Fulmagi gold & 48.56 & 9.05 & 23.93 & 18.57 \\
\hline Geunsame & 58.56 & 6.84 & 23.49 & 24.03 \\
\hline
\end{tabular}
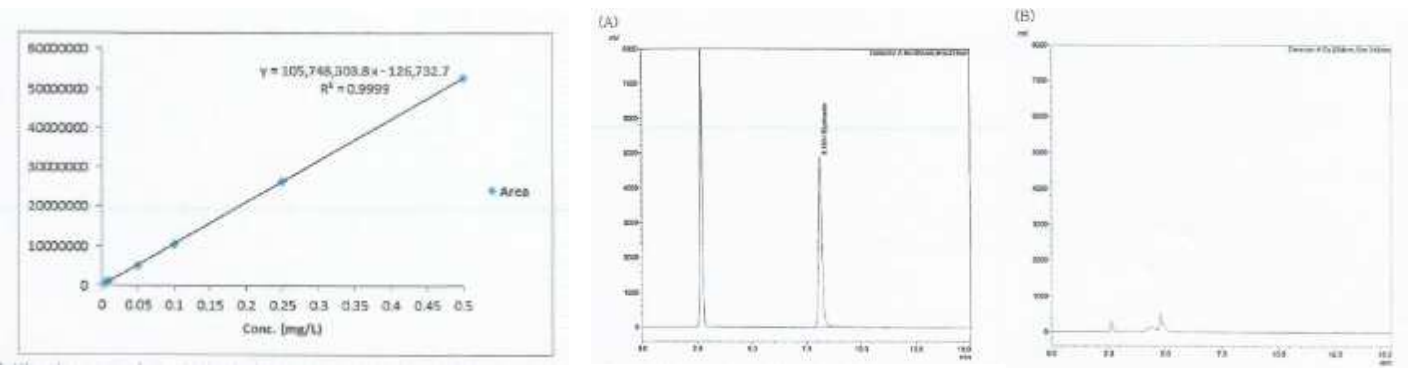

[Fig. 7] Typical Chromatograms of the Standard Solution $(0.5 \mathrm{mg} / \mathrm{L})$

\section{Conclusion}

The types of wild grasses were seed propagation and abandonment, and seed propagation was more dangerous than abandon propagation. As a result of requesting seawater components from Silla University Soil Analysis Center and Mokpo National University, all of them were not detected in tidal-flat soil (cadmium, copper, lead, zinc, nickel) and seawater (sodium chloride, specific gravity, lead, mercury, arsenic). The seawater concentrate as an inhibitor of plant growth had a significant and fast effect on plant death. By using seawater, the period of death was the next day after spraying seawater concentrates. While using herbicides was needed to spray three times to suppress plant growth at 15 days later. The color changed from green color to brown color was only 2 times sprayed with seawater concentrate. When it needed to spray 3 times with pesticides, the rate of plant death was high. Therefore, seawater concentrate was a suitable eco-friendly product that kills sludge and common plants. For future research, it is recommended to do the analysis on the physical properties of soil do the effects will also be known more clearly. 


\section{References}

[1] J. S. Kim, A Research Review for Establishing Effective Management Practices of the Highly Invasive Cordgrass (Spartina spp.), The Korean Society of Weed Science and The Turfgrass Society of Korea, (2016), Vol.5, No.3, pp.111-125. https://doi.org/10.5660/WTS.2016.5.3.111.

[2] E. K. Kim, J. H. Kil, Y. K. Joo and Y. S. Jung, Distribution and Botanical Characteristics of Unrecorded Alien Weed Spartina anglica in Korea, The Korean Society of Weed Science and The Turfgrass Society of Korea, (2015), Vol.4, No.1, pp.65-70. https://doi.org/10.5660/WTS.2015.4.1.65

[3] S. Nehring and K. J. Hesse, The Common Cord-grass Spartina anglica: An Invasive Alien Species in The Wadden Sea National Park, 36th Annual Conference of the Ecological Society of Germany, Switzerland and Austria (GfÖ), (2006), September 11-14; Bremen, Germany

[4] https://www.nobanis.org/globalassets/speciesinfo/s/spartina-anglica/spartina_anglica.pdf, Oct 11 (2015)

[5] X. Zhu, L. Meng, Y. Zhang, Q. Weng and J. Morris, Tidal and Meterological Influences on the Growth of Invasive Spartina alterniflora: Evidence from UAV Remote Sensing, Remote Sensing, (2019), Vol.11, No.10, pp.1208-1225. https://doi.org/10.3390/rs11101208

[6] J. H. Hyun, S. U. An, H. Y. Cho, U. J. Jung, B. M. Kim and H. J. Lee, Effects of Invasive Spartina anglica on Rates and Pathways of Organic Carbon Oxidation in The Intertidal Sediment Inhabited by Native Suaeda japonica in The Han River Estuary, Yellow Sea, 21st EGU General Assembly, (2019), April 7-12; Vienna, Austria 